\title{
Pulmonary Arterial Hypertension Associated with Adult Congenital Heart Disease, when Inoperable becomes Operable: A Case Report
}

Andris Skride ${ }^{1,2}$, Sabine Upmale ${ }^{1}$, Kristaps Sablinskis ${ }^{1}$, Ainars Rudzītis $^{2}$ and Aivars Lejnieks ${ }^{1,3}$

${ }^{1}$ Riga Stradins University, Latvia

${ }^{2}$ Pauls Stradins Clinical University Hospital, Latvia

${ }^{3}$ Riga East Clinical Univeristy Hospital, Latvia

\begin{abstract}
Pulmonary arterial hypertension associated with congenital heart disease (PAH-CHD) is one of the most common forms of pulmonary arterial hypertension (PAH). Unlike the other forms, $\mathrm{PAH}-\mathrm{CHD}$ can be treated surgically closing the extra- or intracardiac shunt if the shunt is left-to-right and the pulmonary vascular resistance (PVR) is low enough (<2,3-operable, 2,3-4,6 WU-borderline operable). If the PAH postoperatively persists the prognosis is even worse than for non-operated patients. Due to the previously mentioned fact the criteria for operability in such cases are often discussed. We report a case of a 54-year-old man who suffers from coronary artery disease (SYNTAX score-23,5) and $\mathrm{PAH}-\mathrm{CHD}$. As the patient required coronary artery bypass grafting (CABG) surgery, the atrial septal defect (ASD) was closed (surgically with a patch followed by transcatheter closure with an occluder) as well despite the fact that according to the current guidelines his pulmonary vascular resistance $(4,7 \mathrm{WU})$ was considered too high for the defect to be operable. The patient was given PAH-specific treatment preoperatively in order to lower his PVR. This article describes the case and discusses the disease, its history, the new classification, diagnostics and treatment options.
\end{abstract}

Keywords: Pulmonary hypertension; Atrial septal defect; Surgical repair; Sildenafil; Congenital heart disease

\section{Background}

Pulmonary arterial hypertension (PAH) is a specific subgroup of pulmonary hypertension (PH). It is characterized by an increased pulmonary pressure and pulmonary vascular resistance which can lead to right ventricular failure [1-4]. PAH is a common complication of congenital heart disease (CHD), which occurs when an intra- or extracardiac shunt exists (Table 1) [5,6]. Such cardiac defects cause $\mathrm{PAH}$ by increasing pressure and volume overload in the right side of the heart, as intimal proliferation and medial hypertrophy increase the resistance of the pulmonary vessels [4]. The UK National PH Audit reported in 2012 that the prevalence of PAH-CHD (30.2\%) was similar to idiopathic PAH (33.6\%) and connective tissue disease-related PAH (28.3\%) of all PAH patients [7]. Atrial septal defect (ASD) is one of the most common congenital heart defects [8]. If PAH is left untreated it can be life-threatening [4]. Therefore we would like to report a case of a 54 year-old-male who was diagnosed with PAH due to an ASD. A high PVR (4.7 WU) was detected. And despite the fact that the current guidelines prohibit such patients (PVR $>4.6 \mathrm{WU}$ ) to undergo surgery, the patient was operated on. The patient's overall status significantly improved.

\section{Case Presentation}

A 54 year-old-male who had been experiencing palpitations due to atrial flutter was admitted to the cardiology ward in June 2008. A transesophageal rhythm restoration was performed. Transesophageal echocardiography (TEE) revealed right atrial and ventricular dilatation, pericardial fluid $(1.7 \mathrm{~cm})$ and an ASD $(2 \mathrm{~cm})$ with a bidirectional shunt, the right ventricular systolic pressure (RVSP) was 85-90 $\mathrm{mmHg}$ therefore pulmonary hypertension was suspected. Laboratory findings showed a high normal erythrocyte level $\left(5.80 \times 10^{12} / \mathrm{L}\right)$ and a slightly elevated $\mathrm{Hb}$ level (178 g/l). High levels of total cholesterol (7.1 $\mathrm{mmol} / \mathrm{l})$, triglycerides $(2.8 \mathrm{mmol} / \mathrm{l})$ and low density lipoprotein $(4.77$ $\mathrm{mmol} / \mathrm{l}$ ) were detected. High density lipoprotein level was low normal (1.06 $\mathrm{mmol} / \mathrm{l})$. His ECG showed sinus rhythm, right axis deviation, severe hypertrophy of the right ventricle and signs of right atrial and ventricular overload (Figure 1). His spirometry test results showed a normal forced vital capacity (FVC) of $80.1 \%$ and a mildly lower

\begin{tabular}{|l|l|l|l|}
\hline $\begin{array}{l}\text { Simple pre- } \\
\text { tricuspid } \\
\text { shunts }\end{array}$ & $\begin{array}{l}\text { Simple post- } \\
\text { tricuspid shunts }\end{array}$ & $\begin{array}{l}\text { Combined } \\
\text { shunts }\end{array}$ & Complex CHD \\
\hline $\begin{array}{l}\text { ASD (Ostium } \\
\text { secundum) }\end{array}$ & VSD & $\begin{array}{l}\text { Combination of } \\
\text { shunts }\end{array}$ & AVSD (partial or complete) \\
\hline $\begin{array}{l}\text { ASD (Sinus } \\
\text { venosus) }\end{array}$ & $\begin{array}{l}\text { Patent ductus } \\
\text { arteriosus }\end{array}$ & & Truncus arteriosus \\
\hline $\begin{array}{l}\text { Total or partial } \\
\text { unobstructed } \\
\text { anomalous } \\
\text { pulmonary } \\
\text { venous return }\end{array}$ & & & $\begin{array}{l}\text { Single ventricle physiology } \\
\text { with unobstructed } \\
\text { pulmonary blood flow }\end{array}$ \\
\hline & & & $\begin{array}{l}\text { Transposition of the great } \\
\text { arteries with VSD (without } \\
\text { pulmonary stenosis) and/ } \\
\text { or patent ductus arteriosus }\end{array}$ \\
\hline
\end{tabular}

Table 1: Anatomical classification of congenital systemic-to-pulmonary shunts associated with PAH [6]. ASD: Atrial Septal Defect; VSD: Ventricualar Septal Defect; AVSD: Atrioventricual Septal Defect.

forced expiratory volume in 1 second (FEV1) of $67.8 \%$. Anomalous pulmonary venous return was excluded on the computed tomography (CT) scan but dilatation of the right atrium with hypertrophy, dilatation of both pulmonary arteries and pericardial fluid $(0.8-1.3 \mathrm{~cm})$ was seen. Coronary angiography was performed and an occlusion of the proximal third of the left anterior descending artery (LAD), a stenosis $(>90 \%)$ of the second obtuse marginal branch (OM2) of the left circumflex artery (LCX), and a stenosis (>75\%) in the mid third of the LCX was detected. Right heart catheterization revealed an atrial septal defect with a left-

*Corresponding author: Aivars Lejnieks, Department of Internal Medicine, Riga Stradins University, Riaga East University hospital, Internal dieses, 2 Hipokrata Riga, LV 1038, Latvia, Tel: 37129554397; Fax: 37167042451; E-mail: lejnieks@ latnet.Iv

Received April 25, 2016; Accepted May 23, 2016; Published May 26, 2016

Citation: Skride A, Upmale S, Sablinskis K, Rudzītis A, Lejnieks A (2016) Pulmonary Arterial Hypertension Associated with Adult Congenital Heart Disease when Inoperable becomes Operable: A Case Report. J Pulm Respir Med 6: 350. doi:10.4172/2161-105X.1000350

Copyright: $\odot 2016$ Skride A, et al. This is an open-access article distributed under the terms of the Creative Commons Attribution License, which permits unrestricted use, distribution, and reproduction in any medium, provided the original author and source are credited. 


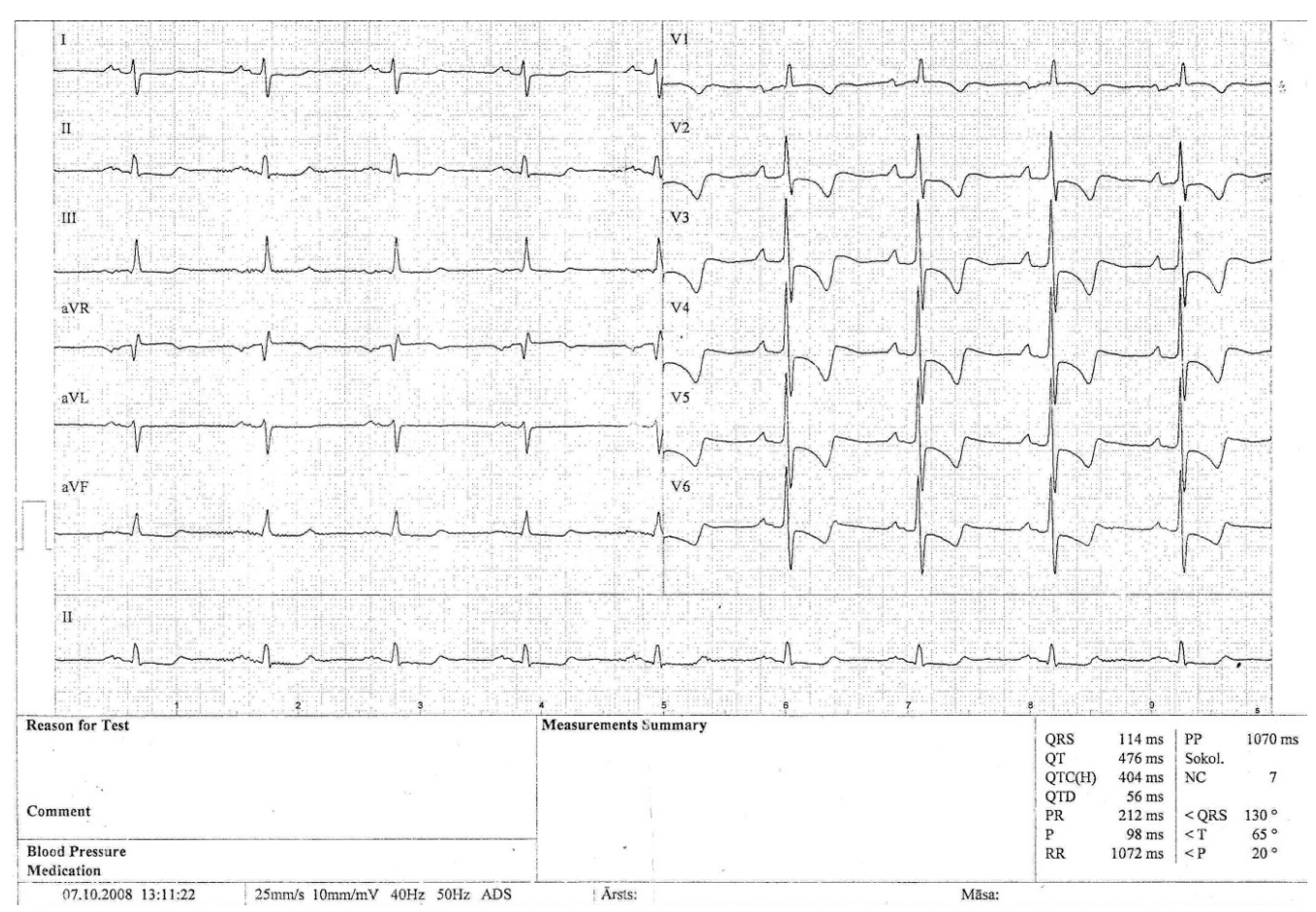

Figure 1: ECG showing sinus rhythm, right axis deviation, severe hypertrophy of the right ventricle and signs of right atrial and ventricular overload.

to-right shunt. The mean pulmonary arterial pressure (mPAP) was 67 mmHg, PVR-4.7 WU, PVRI-2.27 WU/m², Qp-9.81/min, Qs-3.81/min, SVR-22.6 WU, SVRI-10.7 WU/ $\mathrm{m}^{2}$. The patient's oxygen saturation assesed in the femoral artery was $95 \%$ and $94 \%$ in the left pulmonary vein. The patient was recommended to be operated on (ASD closure and coronary artery bypass grafting). PH specific therapy in particular sildenafil 20 TID was prescribed a month prior to surgery and was continued until the defect was closed completely.

In November 2008 percutaneous transcatheter coronary angioplasty (PTCA) was performed in the LCX and the OM2. The patient underwent surgery in February 2009. A longitudinal sternotomy with aortocoronary shunting (LITA-LAD) and closure of the atrial septal defect with a patch $(4 \times 4 \mathrm{~cm})$ leaving a residual $1 \mathrm{~cm}$ in diameter shunt was done. The patient was in the intensive care unit for a day and the rest of the postoperative period went well. After the surgery the patient's right ventricular systolic pressure (RVSP) estimated by echocardiography decreased to $34 \mathrm{mmHg}$.

A follow-up echocardiography was done in June and September 2009. A residual left-to-right shunt of $6 \mathrm{~mm}$ in diameter and dilatation of the left heart was seen. Tricuspid regurgitation II that was seen in June was no longer detectable in September.

In 2010 the patient underwent percutaneous residual shunt closure with an occluder. On echocardiography in 2012 no residual shunt was seen, there was mild dilatation of the right ventricle with the systolic function being intact, both atria mildly dilatated, RVSP-40-45 mmHg, tricuspid regurgitation I-II (Table 2).

The patient was seen on a follow-up visit in November 2015. Right now the patient doesn't take $\mathrm{PH}$-specific medication, he takes acetylsalicylic acid and atorvastatin $40 \mathrm{mg}$ QD. The patient hasn't experienced any of the complications associated with ASD and pulmonary arterial hypertension, has no dyspnea, cyanosis or edema.

\begin{tabular}{|c|c|c|c|c|}
\hline & $\begin{array}{c}\text { Sep 2008 } \\
\text { (TEE) }\end{array}$ & Jun 2009 & Sep 2009 & Sep 2012 \\
\hline RA & $\uparrow \uparrow$ & $53 \times 59 \mathrm{~mm}$ & $\uparrow$ & $30 \mathrm{~cm}^{2}$ \\
\hline $\mathrm{RV}(\mathrm{mm})$ & $\uparrow \uparrow$ & 46 & 47 & 50 \\
\hline LA $(\mathrm{mm})$ & - & 55 & 55 & 58 \\
\hline RVSP $(\mathrm{mmHg})$ & $85-90$ & $75-80$ & - & $40-45$ \\
\hline TR (I-IV) & I & II & 0 & I-II \\
\hline
\end{tabular}

Table 2: Consequent results of the patient's echocardiogram. RA: Right Atrium; RV: Right Ventricle; LA: Left Atrium; RVSP: Right Ventricular Systolic Pressure; TR : Tricuspid Regurgitation. Partial atrial septal defect closure was performed in February 2009 after treatment with Sildenafil for 10 months. Full closure was performed in 2010.

6 minute walk test results were excellent $519 \mathrm{~m}$. His saturation was 93\% before the test and $97 \%$ after the test; he rated his dyspnea as a 2 according to the BORG scale.

\section{Discussion}

Pulmonary arterial hypertension is a progressive disease that is characterized by an increased mean pulmonary arterial pressure of at least $25 \mathrm{mmHg}$ at rest and an elevation of the pulmonary vasular resistance (PVR) of more than $3 \mathrm{WU}$ with a normal pulmonary artery wedge pressure of $\leq 15 \mathrm{mmHg}[1,9,10]$.

Currently it is thought that the pathophysiological cornerstones of pulmonary hypertension are vascular remodelling caused by imbalance between cell proliferation and apoptosis, thrombosis, and the prevalence of vasoconstriction [9].

In 1973 the WHO organized an international conference on PH. Right now according to the WHO classification there are 5 groups of PH [9]. Since 1998 when the working symposia of the WHO was held in Evian, pulmonary arterial hypertension associated with congenital heart disease (PH-CHD) has been classified under the WHO group I, pulmonary arterial hypertension (PAH), along with idiopathic $\mathrm{PH}$, 
familial $\mathrm{PH}$, toxin induced $\mathrm{PH}$, persistent neonatal $\mathrm{PH}$ and $\mathrm{PH}$ due to autoimmune, infectious or hepatic and hematologic causes [11].

One of the most common congenital heart defects is an atrial septal defect (ASD) [8]. It makes $10 \%$ of all CHD and $22-40 \%$ of CHD in adults. The most common is ostium secundum defect $(60-70 \%)$. ASD occurs twice as often in women as in men [12]. It has been reported that out of all patients with pulmonary arterial hypertension $5-10 \%$ have CHD [1]. Yet the prevelance of $\mathrm{PAH}$ in patients with $\mathrm{CHD}$ can vary as the location and size of the defect matter [5]. PAH can be prevented if the cardiac defect is succesfully closed early but operabilty can only be considered for patients with a prevalent left-to-right shunting $[1,5]$. Due to the rapid progress in paediatric cardiology and surgery the number of patients with $\mathrm{PAH}-\mathrm{CHD}$ in western countries has noticeably decreased and the number of patients with CHD who have survived into adulthood has increased [5].

A large ASD is associated with clinical presentation during childhood but mostly the patients are asymptomatic and the disease tends to manifest as the patient gets older $[8,12]$. But even when the patient is asymptomatic, such severe complications as right ventricular failure, atrial arrhythmias, paradoxical embolization, cerebral abscess formation, and pulmonary arterial hypertension that can become irreversible and lead to right-to-left shunting which is called Eisenmenger syndrome can occur [13]. $90 \%$ of the untreated patients develop such symptoms as dyspnea, fatigue, palpitation and persistent arrhythmia by the age of 40 [12]. In case of left-to-right shunting via ASD, symptoms appear when right ventricular volume overload and excessive circulation in the pulmonary system has developed [8].

The physician should always suspect the diagnosis of ASD when the right heart is enlarged without another explanation [14]. Echocardiography can detect the size and location of the ASD, as well as evaluate the shunt and the degree of PAH [12]. Signs of PAH on a chest $\mathrm{x}$-ray include increased lung vascularity, pulmonary vascular congestion, and rib notching. Computed tomography (CT) or magnetic resonance (MRI) can improve the description of the defect. Cardiac catheterization remains the gold standard in detecting the necessary pressures, cardiac output, and PVR and most importantly cardiac catheterization offers the opportunity to correct the defect or to determine whether the patient is suitable for surgery [14].

In the past 10 years PAH treatment options have improved noticeably [15]. Currently there are many oral, intravenous and inhaled drugs. The main pharmacologic groups are calcium channel blockers (CCBs), prostanoids, endothelin-1 receptor antagonists and phosphodiesterase- 5 inhibitors [9]. Patients with PAH-CHD should avoid using CCBs as there is no available data that support their benefit. In patients with Eisenmenger's syndrome CCBs are contraindicated due to the systemic hypotensive effect which can intensify the right-to-left shunt, thus increasing the risk of syncope or even sudden death. According to the BREATHE-5 trial bosentan improves exercise capacity, haemodynamics and functional class in patients with Eisenmenger's syndrome. Sildenafil has been proven to increase exercise tolerability, dyspnea, functional class, the quality of life and haemodynamics in patients with PAH-CHD s well as patients with Eisenmenger's syndrome. Recently there have been many studies investigating whether combined PAH-specific therapy could be beneficial but so far the results are inconclusive. Yet the available data show that PAHspecific treatment definitely improves the outcome [5].

An ASD is closed with a surgical suture or a patch, or via right heart catheterization [13]. It is indicated to close an ASD if an enlargement of the right atrium or the right ventricle is present even in the absence of symptoms. For patients $<25$ years of age the prognosis is excellent after ASD closure. Unfortunately the prognosis for patients of age $>40$ years is poorer than in the general population as this group is predisponed for postoperative arrhythmias [14]. Still it is reported that regardless of age most symptomatic adults experience clinical improvement [8]. According to the 2015 ESC/ERS Guidelines for the diagnosis and treatment of pulmonary hypertension $\mathrm{CHD}$ closure is contraindicated when the PVR is $>4.6$, PVRI $>8$. And in order to achieve the necessary criteria for a surgical defect correction PAH-specific therapy is not recommended [1]. Despite the fact that the patients with a high mPAP and PVR have notable changes of the pulmonary vasculature, there have been several case reports of ASD closure in patients who were borderline operable or inoperable thus the interest in the "treat-toclose" approach has increased $[5,9,16]$. The aim of this approach is to use PAH-specific therapy in order to reduce the PVR thus improving operability.

\section{Conclusion}

This case report emphasizes the importance of the case-by-case approach for evaluation of the PAH-CHD patient's suitability for operation as surgical correction is the most effective way to limit the progression of $\mathrm{PAH}$. $\mathrm{PH}$-specific treatment should always be considered not only to improve the patient's quality of life and decrease the mPAP but also to decrease the PVR thereby potentially readdressing the operability criteria.

\section{References}

1. Galie N, Humbert M, Vachiery JL, Gibbs S, Lang I, et al. (2015) ESC/ERS Guidelines for the diagnosis and treatment of pulmonary hypertension. European Heart Journal 37: 67-119.

2. Beghetti M, Galiè N, Bonnet D (2012) Can "inoperable" congenital heart defects become operable in patients with pulmonary arterial hypertension? Dream or reality? Congenit Heart Dis 7: 3-11.

3. Strumpher J, Jacobson E (2011) Pulmonary hypertension and right ventricular dysfunction: physiology and perioperative management. J Cardiothorac Vasc Anesth 25: 687-704

4. Sharma S (2015) Secondary Pulmonary Hypertension.

5. D'Alto M, Mahadevan VS (2012) Pulmonary arterial hypertension associated with congenital heart disease. Eur Respir Rev 21: 328-337.

6. Simonneau G, Robbins IM, Beghetti M, Channick RN, Delcroix M, et al. (2009) Updated clinical classification of pulmonary hypertension. J Am Coll Cardiol 54: S43-54.

7. Dimopoulos K, Wort SJ, Gatzoulis MA (2014) Pulmonary hypertension related to congenital heart disease: a call for action. Eur Heart J 35: 691-700.

8. Valente AM, Emani SM, Landzberg MJ, Bacha EA (2016) Adult Congenita Cardiac Surgery. Sabiston and Spencer Surgery of the Chest. (9thedn), Elsevier.

9. Andrews JE (2013) Severe Pulmonary Hypertension: A Noncardiac Nonobstetric Surgical Case Study. AANA J 81: 297-302.

10. Oliveira RKF, Ferreira EVM, Ramos RP, Messina CMS, Kapins CEB, et al. (2014) Usefulness of pulmonary capillary wedge pressure as a correlate of left ventricular filling pressures in pulmonary arterial hypertension. J Heart Lung Transplant 33: 157-162.

11. Schulze-Neick I, Deanfield J (2007) Pulmonary Arterial Hypertension in Adults with Congenital Heart Disease: General Overview of Disease Mechanisms. Advances in $\mathrm{PH}$ Journal: 6.

12. Diaconu CC (2011) Atrial septal defect in an elderly woman-a case report. Med Life 4: 91-93.

13. Desai H, Moussa I, George JC (2012) Percutaneous Closure of a Persistent Atrial Septal Defect Following Patch Repair. Cath Lab Digest: 20.

14. Krasuski RA (2010) Congenital Heart Disease in the Adult.

15. Burt C, Pepke-Zaba J, Falter F (2010) Pulmonary arterial hypertension. Curr Vasc Pharmacol 8: 412-420.

16. Nazrin T, Mansur M, Uddin J, Shaha NC, Joarder MAR (2013) Repair of Borderline Operable Atrial Septal Defect with Severe Pulmonary Hypertensionafter Medical Management. Pulse 6: 44-47. 